\title{
Vascular Smooth Muscle Modulates Endothelial Control of Vasoreactivity via Reactive Oxygen Species Production through Myoendothelial Communications
}

\author{
Marie Billaud $^{1,2}$, Roger Marthan ${ }^{1,2}$, Jean-Pierre Savineau ${ }^{1,2}$, Christelle Guibert ${ }^{1,2 *}$ \\ 1 INSERM, U885, Laboratoire de Physiologie Cellulaire Respiratoire, Bordeaux, France, 2 Université de Bordeaux, Bordeaux, France
}

\begin{abstract}
Background: Endothelial control of vascular smooth muscle plays a major role in the resulting vasoreactivity implicated in physiological or pathological circulatory processes. However, a comprehensive understanding of endothelial (EC)/smooth muscle cells (SMC) crosstalk is far from complete. Here, we have examined the role of gap junctions and reactive oxygen species (ROS) in this crosstalk and we demonstrate an active contribution of SMC to endothelial control of vasomotor tone.

Methodology/Principal Findings: In small intrapulmonary arteries, quantitative RT-PCR, Western Blot analyses and immunofluorescent labeling evidenced connexin (Cx) 37, 40 and 43 in EC and/or SMC. Functional experiments showed that the Cx-mimetic peptide targeted against Cx 37 and Cx $43\left({ }^{37,43} \mathrm{Gap} 27\right)(1)$ reduced contractile and calcium responses to serotonin (5-HT) simultaneously recorded in pulmonary arteries and (2) abolished the diffusion in SMC of carboxyfluorescein-AM loaded in EC. Similarly, contractile and calcium responses to 5-HT were decreased by superoxide dismutase and catalase which, catabolise superoxide anion and $\mathrm{H}_{2} \mathrm{O}_{2}$, respectively. Both $\mathrm{Cx}$ - and ROS-mediated effects on the responses to 5-HT were reversed by L-NAME, a NO synthase inhibitor or endothelium removal. Electronic paramagnetic resonance directly demonstrated that 5-HT-induced superoxide anion production originated from the SMC. Finally, whereas 5 -HT increased NO production, it also decreased cyclic GMP content in isolated intact arteries.

Conclusions/Significance: These data demonstrate that agonist-induced ROS production in SMC targeting EC via myoendothelial gap junctions reduces endothelial NO-dependent control of pulmonary vasoreactivity. Such SMC modulation of endothelial control may represent a signaling pathway controlling vasoreactivity under not only physiological but also pathological conditions that often implicate excessive ROS production.
\end{abstract}

Citation: Billaud M, Marthan R, Savineau J-P, Guibert C (2009) Vascular Smooth Muscle Modulates Endothelial Control of Vasoreactivity via Reactive Oxygen Species Production through Myoendothelial Communications. PLoS ONE 4(7): e6432. doi:10.1371/journal.pone.0006432

Editor: Neeraj Vij, Johns Hopkins School of Medicine, United States of America

Received March 24, 2009; Accepted June 26, 2009; Published July 30, 2009

Copyright: (c) 2009 Billaud et al. This is an open-access article distributed under the terms of the Creative Commons Attribution License, which permits unrestricted use, distribution, and reproduction in any medium, provided the original author and source are credited.

Funding: This work was supported by grants from Agence Nationale de la Recherche (ANR06 - Physio - 015 - 01) and the Fondation de France (2008002719). Marie Billaud received a grant from GRRC (Groupe de Reflexion sur la Recherche Cardiovasculaire) to improve her technical skills. The funders had no role in study design, data collection and analysis, decision to publish, or preparation of the manuscript.

Competing Interests: The authors have declared that no competing interests exist.

* E-mail: christelle.guibert@u-bordeaux2.fr

\section{Introduction}

In vessels, smooth muscle cell (SMC) responses are controlled by endothelial cells $(\mathrm{EC})$ via complex intercellular signaling processes. Regarding vascular tone, the best described interaction is the endothelial-dependent vascular relaxation through the release of nitric oxide (NO) and vasoactive prostanoids [1]. Another pathway is associated with the hyperpolarization of both the EC and SMC and mediated by an endothelium-derived hyperpolarizing factor (EDHF). Whereas EDHF identity is still under debate and may differ among species and vascular segments, there is evidence that EDHF-mediated responses involve epoxyeicosatrienoic acids (EETs) [2], potassium ions and channels [3], reactive oxygen species (ROS) such as hydrogen peroxide $\left(\mathrm{H}_{2} \mathrm{O}_{2}\right)$ [4] and myoendothelial junctions [5].

In the pulmonary circulation, endothelial control of smooth muscle tone is of critical importance to maintain low pressure and low resistance. In this connection, most of the medical treatments used in pulmonary hypertension (e.g., NO, prostacyclin...) mimic and amplify the physiological control of EG on SMC. For instance, serotonin (5-HT), a potent vasoconstrictor whose concentration is increased in pulmonary arterial hypertension $(\mathrm{PAH})[6,7]$, acts on both SMC and EC. On one hand, 5-HT can generate NO in pulmonary arterial EC [8]. On the other hand, 5HT produces ROS in bovine and mice pulmonary arterial SMC and the production of superoxide anion $\left(\mathrm{O}_{\overline{2}}^{\dot{*}}\right)$ facilitates 5-HTinduced pulmonary vasoconstriction $[9,10] . \mathrm{O}_{\overline{2}}^{\dot{*}}$ can interact with $\mathrm{NO}$ to produce peroxynitrite which decreases endothelial NO synthase (eNOS) expression and/or loss of eNOS substrate Larginine or cofactors tetrahydrobiopterin $(\mathrm{BH} 4)$ [11]. We thus hypothesized an EC/SMC crosstalk through $\mathrm{NO}$ and $\mathrm{O}_{2}^{\dot{2}}$. Gap junctions mediate intercellular communication between EG and SMC (myoendothelial gap junctions) and allow direct exchange of ions and small molecules in various tissues including pulmonary arteries [5,12]. Whereas gap junctions are expressed in pulmonary artery $[13,14]$, participate to vascular tone in general [12] and are stimulated by 5 -HT in coronary and mesentery SMC [15], no study has been performed on the role of gap junctions in the 
pulmonary arterial vasoreactivity to 5 -HT. Such communication may well participate to the EC/SMC crosstalk. Interestingly, resistance vessels are very important for blood flow regulation and the incidence of myoendothelial gap junctions is higher in resistance than in conduit arteries [16].

In the present study, we have therefore addressed, in small intrapulmonary arteries (IPA), the issue of expression, localization and function of the connexins $(\mathrm{Cx}) 37,40$ and 43 which are the $\mathrm{Cx}$ usually expressed in small vessels. Peptides homologous to the gap 26 and 27 domains of the extracellular loops of $\mathrm{Cx} 43\left({ }^{43} \mathrm{Gap} 26\right)$ or $\mathrm{Cx} 37$ and $43\left({ }^{37-43} \mathrm{Gap} 27\right)$ respectively, interrupt intercellular communications in a Cx-specific manner and attenuate the calcium and contractile responses to 5-HT. Such effect was reversed by (1) the removal of the endothelium-dependent NO function or (2) the decrease of ROS production. Electronic paramagnetic studies demonstrated that ROS and more specifically $\mathrm{O}_{2}^{-}$was produced by the smooth muscle in response to 5 -HT. In the same way, the NO and cyclic GMP content were assessed in response to 5 -HT.

Altogether, the findings suggest that 5 -HT produces $\mathrm{O}_{2}^{-}$in the smooth muscle and $\mathrm{NO}$ in the endothelium. $\mathrm{O}_{2}^{-}$passes through the myoendothelial junctions to decrease endothelial $\mathrm{NO}$ production and thus strengthen pulmonary vasoreactivity. This is the first time that a negative control of the endothelial NO function by the smooth muscle is demonstrated. Since ROS production is increased in many cardiovascular diseases, such process could be of great importance under pathological conditions.

\section{Materials and Methods}

\section{Ethics Statement}

All animal work has been conducted according to relevant international and national guidelines in accordance with the recommendations of the Weatherall report, "The use of nonhuman primates in research". All the protocols used were approved by our local ethics committee named Comité d'éthique régional d'Aquitaine. The protocol number is AP 2/11/2005.

\section{Tissue Preparation}

Male Wistar rats (10-15 weeks old, weighing 300-400 g) were sacrificed using $\mathrm{CO}_{2}$ asphyxia according to the animal care and use local committee (Comité d'éthique régional d'Aquitaine - AP $2 / 11 / 2005)$. The left lung was rapidly removed and rinsed in Krebs-HEPES-bicarbonate containing (in $\mathrm{mM}$ ): $118.4 \mathrm{NaCl}, 4.7$ $\mathrm{KCl}, 1.2 \mathrm{MgSO}_{4}, 4 \mathrm{NaHCO}_{3}, 1.2 \mathrm{KH}_{2} \mathrm{PO}_{4}, 2 \mathrm{CaCl}_{2}, 10 \mathrm{~N}-2-$ hydroxyethylpiperazine-N'-2-ethanesulfonic acid (HEPES) and 6 D-glucose, $\mathrm{pH} 7.4$ with $\mathrm{NaOH}$. Intrapulmonary arteries with an external diameter of 300-350 $\mu \mathrm{m}$ (IPA) were then dissected free from surrounding connective tissues under binocular control.

\section{Intracellular Calcium and External Diameter Recording}

IPA were cannulated as previously described [17] in an arteriograph (DMT, Denmark). Residual blood was removed by perfusing the vessels with Krebs-HEPES solution, and then vessels were maintained in a no-flow state and held at a constant transmural pressure of $10 \mathrm{mmHg}$ and at a constant temperature of $37^{\circ} \mathrm{C}$. Vessels were incubated $1 \mathrm{~h}$ in $2 \mu \mathrm{M}$ Fura-PE3-AM at $37^{\circ} \mathrm{C}$ and rinsed for $10 \mathrm{~min}$ with Krebs-HEPES solution. The arteriograph was then placed on the stage of an inverted epifluorescence microscope (Olympus IX70) equipped with a x10, UPlanApo/0.40 W water-immersion objective (Olympus). The source of excitation light was a xenon arc lamp $(175 \mathrm{~W})$, and excitation wavelengths were selected by a wheelfilter (Sutter
Instrument Co.) composed of $345 \mathrm{~nm}$ and $380 \mathrm{~nm}$ filters. Digital images were sampled at 12-bit resolution by a fast-scan, cooled charge-coupled device camera (CoolSNAP fx Monochrome, Photometrics). Preparation was then alternately excited at 345 and $380 \mathrm{~nm}$ and emission fluorescence at $510 \mathrm{~nm}$ of both excitation wavelengths was imaged every 20 seconds. As previously described, regions of interest were drawn on the vascular wall to determine calcium signal from smooth muscle cells and background was substracted using MetaFluor (Universal Imaging Software) [17]. External diameter of the vessels was measured on these images using MetaMorph (Universal Imaging Software). Contraction was expressed as a percentage related to the percentage of decrease of the initial external diameter.

Either $10 \mu \mathrm{M}$ or cumulative concentrations of 5-HT (Sigma) were added to the bath, which was bubbled with air. After recording of this first contraction, vessels were washed and pharmacological substances were added both to the bath and to the perfusion solution inside the vessel for one hour. We inhibited gap junction communications through $\mathrm{Cx} 37$ and $\mathrm{Cx} 43, \mathrm{Cx} 40$, or Cx 43 with synthetic connexin-mimetic peptides: ${ }^{37,43}$ Gap 27 (SRPTEKTIFII), ${ }^{40}$ Gap 27 (SRPTEKNVFIV) and ${ }^{43}$ Gap 26 (VCYDKSFPISHVR) respectively (Genscript). Specificity of these peptides was checked with an inactive homologous peptide: ${ }^{43} \mathrm{Gap}$ 20 (EIKKFKYGC). The role of superoxide anion was investigated with $300 \mathrm{U} / \mathrm{ml}$ poly-ethylene glycol-superoxide dismutase (PEGSOD, Sigma) combined to $600 \mathrm{U} / \mathrm{ml}$ poly-ethylene glycol-catalase (PEG-catalase; Sigma). Once substances added, a second contraction with either $10 \mu \mathrm{M}$ or cumulative concentrations of 5-HT was performed. We performed time-matched controls to check that we can produce two similar cumulative concentration-response curves (CGRG) to 5-HT with one hour of delay between the two CGRG (Figure S1). When indicated, vessels were perfused before contraction protocol with $100 \mu \mathrm{l}$ of $0.3 \% 3$-((3-cholamidopropyl)diethylammonio)-1-propane sulphonate (CHAPS, Sigma) in order to remove endothelium, as previously described [18].

We checked that such protocol suppressed endothelial function by testing the absence of a relaxation with $10 \mu \mathrm{M}$ carbamylcholine of $40 \mathrm{mM} \mathrm{KCl}$-induced preconstricted pulmonary arteries (Figure S2). CHAPS on its own had no deleterious effect on the contraction and calcium signal induced by high potassium solution (KCl $40 \mathrm{mM}$ ) (Figure S3).

\section{Isometric Contraction Measurements}

Isometric contraction was recorded in intrapulmonary arterial rings with an external diameter of $1.5-2 \mathrm{~mm}$ as reported previously [19,20]. Briefly, mechanical properties were assessed using organ bath and transducer systems, coupled to IOX software (EMKA Technologie). As determined in preliminary experiments, tissues were set at optimal length by equilibration against a passive load of $0.8 \mathrm{~g}$. At the outset of each experiment, $\mathrm{K}^{+}$-rich $(80 \mathrm{mM})$ solution, obtained by substituting an equimolar amount of $\mathrm{KCl}$ for $\mathrm{NaCl}$ from Krebs-HEPES solution, was applied in order to obtain a reference contraction used to normalize subsequent contractile responses. Contractile properties were tested by constructing a CGRG to 5 -HT $(10 \mathrm{nM}$ to $100 \mu \mathrm{M})$ for each ring. When indicated, ${ }^{37,43}$ Gap 27 was incubated during 1 hour before CCRC to 5 -HT.

Endothelial function was tested by relaxation with $10 \mu \mathrm{M}$ carbamylcholine of $0.3 \mu \mathrm{M}$ phenylephrine-induced preconstricted pulmonary arterial rings. All experiments were performed at $37^{\circ} \mathrm{C}$.

\section{Quantitative RT-PCR}

RNA Extraction. IPA from one rat was homogenized using $600 \mu \mathrm{l}$ of Trizol (Invitrogen), then, $120 \mu \mathrm{l}$ of chloroform (Sigma) 
was added. The RNA was extracted from the aqueous phase after centrifugation at $15,000 \mathrm{~g}$ for $15 \mathrm{~min}$. RNA was precipitated in the presence of isopropanol (Sigma) at $-20^{\circ} \mathrm{C}$ overnight. The pure RNA was obtained by centrifugation at $15,000 \mathrm{~g}$ for $15 \mathrm{~min}$ and was washed with $80 \%$ ethanol (Sigma). The concentration of RNA was measured spectrophotometrically by GeneQuant RNA/DNA calculator (Amersham Pharmacia). The total RNA (1 $\mu \mathrm{g}$ ) was reverse transcribed into cDNA by using AMV reverse transcriptase (Promega), RNase inhibitor, and oligo $\mathrm{d}(\mathrm{T})$ as a primer at $42^{\circ} \mathrm{C}$ for $60 \mathrm{~min}$ followed by heating at $94^{\circ} \mathrm{C}$ for $3 \mathrm{~min}$.

Real-time Quantitative Polymerase Chain Reaction (PCR). Real-time quantitative PCR was performed with a Rotor-Gene 2000 (Corbett Research). Triplicate PCR reactions were assembled in $0.1-\mathrm{ml}$ strip tubes containing cDNA from $10 \mathrm{ng}$ of total RNA, $0.2 \mu$ of $50 \times$ Titanium Taq DNA Polymerase combined to its buffer (Clontech Laboratories), $1 \mathrm{mM}$ dNTP, each of the appropriate primer (Sigma Genosys; see table 1 for concentrations and sequences), and $0.5 \times$ SYBR Green (Molecular Probes).

The PCR was performed under the following conditions: denaturation at $95^{\circ} \mathrm{C}$ for $15 \mathrm{~s}$, annealing temperature $\left(68-70^{\circ} \mathrm{C}\right)$ depending on specific primers for $15 \mathrm{~s}$, and extension at $70^{\circ} \mathrm{C}$ for $15 \mathrm{~s}$, these steps were repeated during 40 cycles. Data collection was performed after each extension step, at a temperature of at least $3.5^{\circ} \mathrm{C}$ lower than the melting temperature of the amplicon (generally between $80-85^{\circ} \mathrm{C}$ ) to eliminate non-specific fluorescence signal. PCR negative controls were systematically made by using water instead of cDNA. All specific primers were designed by using the primer analysis software (Oligo 6.6, Molecular Biology Insights). The efficiency of the PCR reactions was always more than $90 \%$. Specificity of the amplified PCR products was checked with melting curve analysis and by electrophoresis analysis on a $2 \%$ agarose gel containing SYBR Green.

\section{Western Blot}

IPA from 4 rats were homogenized on ice in lyses buffer containing $1 \%$ IGEPAL, $0.5 \%$ sodium deoxycholate, $0.1 \%$ SDS, $1 \mathrm{mM}$ amino-ethyl-benzenesulfonyl fluoride hydrochloride (AEBSF), $1.5 \mu \mathrm{M}$ aprotinin and $0.1 \mathrm{mM}$ leupeptin (Sigma-Aldrich). After 10 minutes of centrifugation at $15,000 \mathrm{~g}$, supernatant is reduced in Laemmli buffer and heated at $90^{\circ} \mathrm{C}$ for 6 min. Protein extract were subjected to electrophoresis on a $10 \%$ acrylamid reducing gel, and transferred to polyvinylidene fluoride (PVDF) membranes (Immobilon-P, Millipore). The immunoblots were then incubated using either rabbit anti-Cx 37, rabbit anti-Cx 40 or mouse anti-Cx 43 (Zymed) overnight at $4^{\circ} \mathrm{C}$. After incubation with appropriate secondary antibodies coupled to horseradish peroxydase (HRP, Santa Cruz) for $2 \mathrm{~h}$ at room temperature, immunoblots were then revealed by enhanced chemiluminescence acquired using Kodak Image Station 4000 MM. Band densities were quantified using GeneTool software (SynGene). Immunoblots were then stripped and revealed with mouse anti- $\beta$-actin for $1 \mathrm{~h}$ at room temperature.

\section{Immunofluorescence}

IPA were fixed in Formalin (Sigma) for $10 \mathrm{~min}$ and then embedded in OCT-Compound, frozen at $-20^{\circ} \mathrm{C}$ and cut in $10 \mu \mathrm{m}$ sections with a cryostat. Sections were first incubated in $0.1 \%$ Triton X-100 (Sigma) and 1\% bovine serum albumin in PBS for $1 \mathrm{~h}$ at room temperature, and then in the primary antibodies (same antibodies as the ones used for Western Blot) overnight at $4^{\circ} \mathrm{C}$. Sections were then incubated with the appropriate secondary antibodies coupled to Alexa 546 (Molecular Probes) for $2 \mathrm{~h}$ at room temperature. Nuclei were labeled with $45 \mu \mathrm{M}$ Hoechst 33342 (Molecular Probes). Sections were then observed with a laser scanning confocal microscope TE2000 (Nikon) with a x 60, 1.40 NA plan apochromat oil-immersion objective. Excitation was obtained with a diode laser at $408 \mathrm{~nm}$ to observe nuclei, an argon laser at $488 \mathrm{~nm}$ to observe autofluorescence of the internal elastic lamina and a helium-neon laser at $543 \mathrm{~nm}$ to observe $\mathrm{Cx}$ labeling. The emitted light was filtered as appropriate: $450 \pm 35 \mathrm{~nm}$ for nuclei (blue), $515 \pm 30 \mathrm{~nm}$ for internal elastic lamina (green), and $605 \pm 75 \mathrm{~nm}$ for Cx labeling (red).

\section{Dye Transfer}

IPA were mounted in an arteriograph as previously described (see Intracellular calcium and external diameter recording). The vessels were allowed to equilibrate and pressurized at $10 \mathrm{mmHg}$ for $30 \mathrm{~min}$, and then lumen was loaded with $10 \mu \mathrm{M}$ carboxyfluorescein-AM (Molecular Probes) for $30 \mathrm{~min}$ before washout with Krebs-HEPES for $30 \mathrm{~min}$. Where indicated, vessels were perfused with $300 \mu \mathrm{M}{ }^{37,43}$ Gap 27 for 1 h before carboxyfluorescein loading. Vessels were subsequently removed from the

Table 1. Sequences of the primer pairs (S: sense; AS: antisense) for housekeeping genes (GAPDH, HPRT, PLRPO and YWHAZ) and genes of interest $(C \times 37, C x 40$ and Cx 43) are shown as well as GenBank accession number, product length, product Tm and concentrations.

\begin{tabular}{|c|c|c|c|c|c|}
\hline Gene & Sequence & GenBank accession number & Product length (pb) & Product Tm $\left({ }^{\circ} \mathrm{C}\right)$ & Concentration (nM) \\
\hline GAPDH & $\begin{array}{l}\text { S: ATTCTACCCACGGCAAGTT } \\
\text { AS: CGCCAGTAGACTCCACGACATA }\end{array}$ & NM_017008 & 153 & 89.4 & 200 \\
\hline HPRT & $\begin{array}{l}\text { S: TGTTGGATATGCCCTTGACTA } \\
\text { AS: AGATGGCCACAGGACTAGAAC }\end{array}$ & NM_012583 & 178 & 85.6 & 100 \\
\hline PLRPO & $\begin{array}{l}\text { S: AGGTGGGAGCCAGCGAAGC } \\
\text { AS: GCAACAGTCGGGTAGCCAATC }\end{array}$ & NM_022402 & 208 & 91.7 & 100 \\
\hline YWHAZ & $\begin{array}{l}\text { S: AGCCGAGCTGTCTAACGAG } \\
\text { AS: GCCAAGTAGCGGTAGTAGTCA }\end{array}$ & NM_013011 & 291 & 88.4 & 100 \\
\hline Cx 37 & $\begin{array}{l}\text { S: GGTGGCAGAGGACGGTCGTCT } \\
\text { AS: CCATGGTCCAGCCGTAGAGA }\end{array}$ & NM_021654 & 133 & 85.3 & 200 \\
\hline Cx 40 & $\begin{array}{l}\text { S: GGAAAGAGGTGAACGGGAAG } \\
\text { AS: GGGCCTCGAGACATAACAGTT }\end{array}$ & NM_01280 & 197 & 91.3 & 200 \\
\hline Cx 43 & $\begin{array}{l}\text { S: TCTGCCTITCGCTGTAACACT } \\
\text { AS: GGGCACAGACACGAATATGAT }\end{array}$ & NM_012567 & 117 & 87.5 & 200 \\
\hline
\end{tabular}


arteriograph and fixed in Formalin for $20 \mathrm{~min}$ at room temperature before cryopreservation in OCT compound at $-20^{\circ} \mathrm{C}$. Cryosections $(10 \mu \mathrm{m}$ thick $)$ were prepared and mounted in Fluorescent mounting medium (Dako) and imaged with laser scanning confocal microscope TE2000 (Nikon) with a x 60, 1.40 NA plan apochromat oil-immersion objective. Preparation was excited with an argon laser at $488 \mathrm{~nm}$, and fluorescence emission was filtered at $515 \mathrm{~nm} \pm 30$.

\section{Electron Paramagnetic Resonance (EPR) Recordings}

Intrapulmonary arteries with an external diameter of $0.3-2 \mathrm{~mm}$ were used for EPR studies and cGMP measurements.

Superoxide Anion Spin Trapping. Pulmonary arteries were incubated in the spin trap solution containing $500 \mu \mathrm{M}$ 1-hydroxy-3methoxycarbonyl-2,2,5,5-tetramethylpyrrolidin (CMH, Noxygen), $25 \mu \mathrm{M}$ deferoxamine (Sigma) and $5 \mu \mathrm{M} \quad \mathcal{N}$, $\mathcal{N}$-diethyldithiocarbamate (DETC, Sigma) in Krebs-HEPES at $37^{\circ} \mathrm{C}$ for $45 \mathrm{~min}$. 5-HT $0.1 \mathrm{mM}$ was added during the spin trap incubation; PEGSOD $300 \mathrm{U} / \mathrm{mL}$ was incubated during $45 \mathrm{~min}$ before spin trap incubation. Reaction was stopped by freezing the sample in liquid nitrogen. Samples were then analyzed by EPR spectrometry on a tabletop x-band spectrometer miniscope (MS200, Magnettech). Spectra of the oxidized product of CMH $(\mathrm{GM} \bullet)$ were recorded at $77^{\circ} \mathrm{K}$ using a flask Dewar. Acquisition parameters were as followed: Bo Field: $3341 \pm 150 \mathrm{G}$, microwave power: $10 \mathrm{~dB}$, amplitude modulation: $5 \mathrm{G}$, sweep time: $60 \mathrm{sec}$, gain: 300 and 3 scans [21]. Signals were quantified by measuring the total amplitude, after correction of baseline and normalized to the protein quantity of the sample in $\mathrm{mg} / \mathrm{ml}$.

NO Spin Trapping. Detection of NO production was performed using the technique with $\mathrm{Fe}^{2+}$-DETC as spin trap. IPA were placed in $0.5 \mathrm{ml}$ of Krebs-HEPES and then treated with $0.5 \mathrm{ml}$ of colloid $\mathrm{Fe}(\mathrm{DETC})_{2}$ as previously described and incubated for $45 \mathrm{~min}$ at $37^{\circ} \mathrm{C}$ [22]. When indicated, $0.1 \mathrm{mM} \mathrm{5-}$ $\mathrm{HT}$ was added during $\mathrm{Fe}(\mathrm{DETC})_{2}$ incubation. NO measurements were performed at $77^{\circ} \mathrm{K}$ using EPR spectrometry. Instrument settings were: Bo Field: $3285 \pm 80 \mathrm{G}$, microwave power: $10 \mathrm{~dB}$, amplitude modulation: $7 \mathrm{G}$, sweep time: $150 \mathrm{sec}$, gain: 900 and 3 numbers of scan. Signals were quantified by measuring the total amplitude, after correction of baseline and normalized to the protein quantity of the sample in $\mathrm{mg} / \mathrm{ml}$.

\section{cGMP Measurements}

Intrapulmonary arteries were incubated in Krebs-HEPES with or without 5-HT $0.1 \mathrm{mM}$ and with or without PEG-SOD + PEGcatalase $\left(300 \mathrm{U} / \mathrm{ml}\right.$ and $600 \mathrm{U} / \mathrm{ml}$ respectively) at $37^{\circ} \mathrm{C}$ for $15 \mathrm{~min}$, cooled in liquid nitrogen and then stored at $-80^{\circ} \mathrm{C}$. Arteries were homogenized in ice-cold trichloroacetic acid $(5 \%$, Sigma) to extract cGMP. cGMP content was assayed as described in the procedure of an ELISA kit obtained from Cayman Chemical \& Co. cGMP level was normalized to tissue protein content in $\mathrm{mg} / \mathrm{ml}$.

\section{Statistical Analysis}

All results are expressed as means \pm SEM, $n$ indicates the number of IPA for the calcium and contractile studies, dye transfer and immunofluorescence, the number of rats for quantitative RTPCR, EPR and cGMP measurements, and the number of experiments from 3 pools of rats (4 rats per pool) for Western Blot. Cumulative concentration response curves to 5-HT were fitted to the logistic equation with Origin 6.0 software to determine the maximum effect of 5-HT for each experiment, and a non parametric test for paired samples (Wilcoxon test) was performed on the maximum effect of 5-HT with or without drug.
Quantitative RT-PCR results were analyzed with the GeNorm method [23]. Statistical analyses were performed on all other data using a non parametric test for unpaired samples (Mann-Witney test). Values of $P<0.05$ were considered significant.

\section{Results}

Connexins 37, 40 and 43 are expressed and functional in the pulmonary arterial wall

Although very few studies have been performed with controversial results in pulmonary arteries, the three $\mathrm{Cx} 37,40$ and 43 have been observed in pulmonary arteries [13,14]. Quantitative RT-PCR and Western Blot experiments evidenced the presence of the mRNA and proteins for the three $\mathrm{Cx} 37,40$ and 43 in small intrapulmonary arteries (IPA) (Figure 1A and B). Immunofluorescent labeling studies confirmed the presence of the $\mathrm{Cx} 37,40$ and 43 proteins (Figure 1C). The autofluorescence of the external and internal elastic lamina in green has been previously observed in various vessels $[24,25]$ and is useful to delimit the smooth muscle layers from the endothelial cells and the adventitia. Some punctate labeling was observed for the $\mathrm{Cx} 37,40$ and 43 in the endothelium and similar labeling was observed in the smooth muscle for the $\mathrm{Cx}$ 37 and 40 (Figure 1C). Punctate staining is characteristic of connexins labeling and has been previously shown in various tissues including vessels [4,24,25]. Since (1) Cx 37 and 43 are expressed in IPA, (2) they have a functional role in both the calcium and contractile signal and (3) they are localized in the endothelium, we then addressed the functional role of the $\mathrm{Cx} 37$ and 43 in the myoendothelial communications and/or the communications between endothelial cells. After loading endothelial cells with a fluorescent dye (carboxyfluorescein), the dye diffused to the smooth muscle cells in control conditions (Figure 1D left) whereas it stayed in the endothelium when the vessels were pretreated with ${ }^{37,43}$ Gap $27300 \mu \mathrm{M}$ (Figure 1D right).

Altogether, it can be concluded that the myoendothelial communications are functional and involve the $\mathrm{Cx} 43$ and/or Cx 37.

\section{Vasoreactivity to $5-\mathrm{HT}$ is controlled by gap junctions and endothelium}

We then examined if gap junctions had any influence on (1) the intracellular calcium concentration in smooth muscle and (2) the contraction in IPA. Consequently, we checked if any of these connexins had any role in the simultaneously recorded calcium and contractile signals in response to the agonist 5-HT in IPA. Incubation of the vessels with ${ }^{40} \mathrm{Gap} 27300 \mu \mathrm{M}$, the $\mathrm{Cx}$-mimetic peptide used as a specific blocker of the $\mathrm{Cx} 40$, had no effect on both calcium and contractile signals (Figure S4). In contrast, incubation with ${ }^{37,43}$ Gap $27300 \mu \mathrm{M}$, the Cx-mimetic peptide used as a specific blocker of the both $\mathrm{Cx} 37$ and 43, strongly decreased both calcium and contractile signals to 5-HT (Figure 2A and B left). Incubation with ${ }^{43} \mathrm{Gap} 26300 \mu \mathrm{M}$, the specific blocker of the $\mathrm{Cx} 43$ alone, had similar effects on calcium and contractile signals to those of the ${ }^{37,43}$ Gap 27 (Figure S5) suggesting that the $\mathrm{Cx} 43$ is involved in the response to 5 -HT. Since ${ }^{43}$ Gap 20 is a peptide homologous to the intracellular loop of the $\mathrm{Cx} 43$, it can be used as an inactive analog of the Gap 27 specific of the Cx 43 [26]. We observed that ${ }^{43} \mathrm{Gap} 20300 \mu \mathrm{M}$ had no effect on the calcium and contractile signals to 5-HT confirming the specificity of these Cx-mimetic peptides (Figure S6).

Since gap junctions are localized in between smooth muscle cells and/or in between endothelial cells and/or in between smooth muscle and endothelial cells (myoendothelial junctions), we removed the endothelium of the vessels to discriminate the role 
A

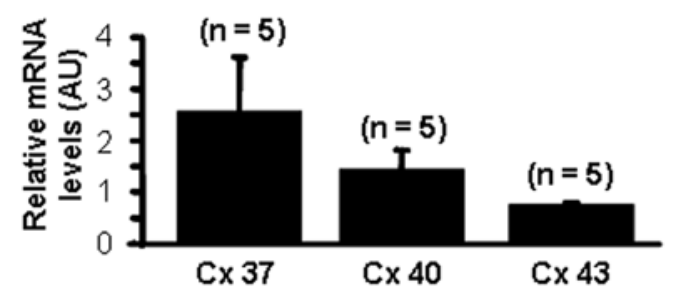

B

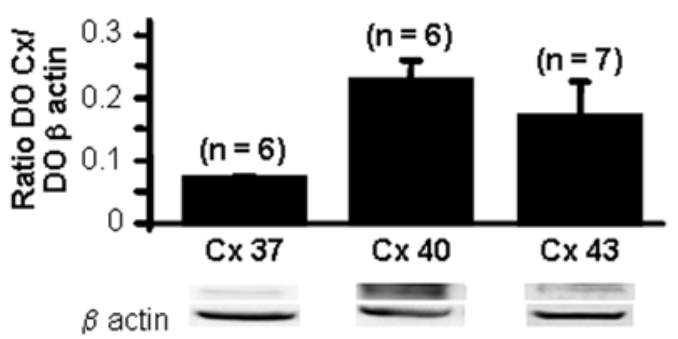

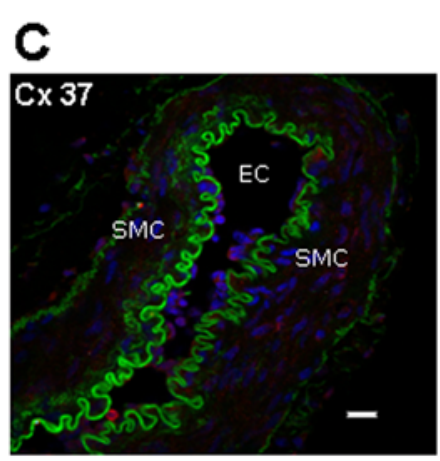
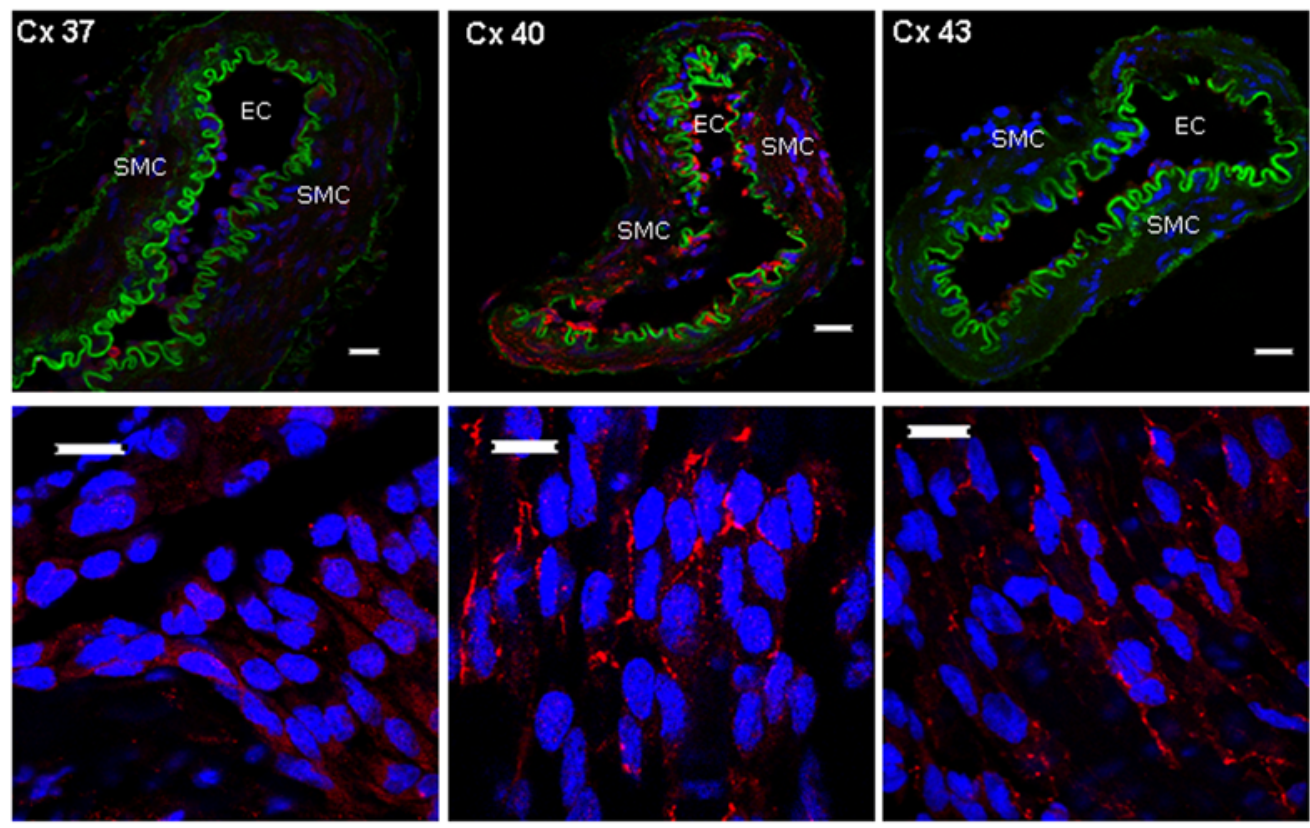

D
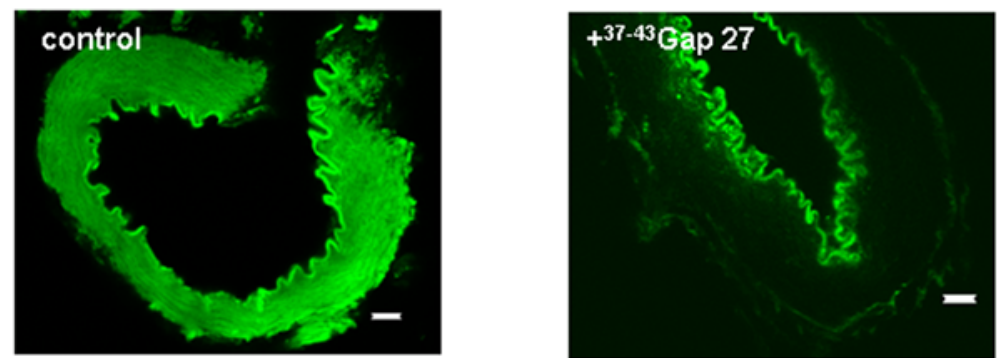

Figure 1. Expression and function of connexins $\mathbf{3 7}, \mathbf{4 0}$ and $\mathbf{4 3}$. A shows mean values \pm S.E.M. of relative mRNA expression levels measured by quantitative RT-PCR. B shows protein expression measured by Western Blot and normalized to $\beta$ actin expression level. C shows immunofluorescent labeling demonstrating the presence of $\mathrm{Cx}$ (red) 37 (left), 40 (middle) and 43 (right). Green shows the autofluorescent signal of the vessels and blue the nuclei (C). C bottom are pictures of the endothelial side of opened vessels. SMC means smooth muscle cells and EC means endothelial cells. D shows diffusion of a green fluorescent dye from the endothelium to the smooth muscle via cell-to-cell communications in basal conditions (left) and such diffusion was blocked following one hour incubation with $300 \mu \mathrm{M}^{37-43} \mathrm{Gap} 27$ (right). Scale bars are $15 \mu \mathrm{m}$. $\mathrm{n}$ indicates the number of rats for quantitative RT-PCR and the number of experiments performed for Western Blot.

doi:10.1371/journal.pone.0006432.g001

of these different types of communications. The blocking effect of the ${ }^{37,43}$ Gap $27300 \mu \mathrm{M}$ was absent in endothelium-denuded vessels (Figure 2B right) suggesting that the myoendothelial and/or the endothelial junctions are important for the calcium and contractile signals to 5-HT.

Isometric tension recordings showed that whereas ${ }^{37,43}$ Gap 27 $300 \mu \mathrm{M}$ blocked the CCRC to 5-HT $(0.01-100 \mu \mathrm{M})$, it had no effect on the CCRG to phenylephrine $(0.1 \mathrm{nM}-3 \mu \mathrm{M})$, to endothelin-1 (0.1-5000 nM) and to high potassium solutions (4.7-
$100 \mathrm{mM}$, Figure S7). Moreover, in systemic vessels such as renal arteries, the CGRC to 5-HT were identical in the presence or in the absence of ${ }^{43} \mathrm{Gap} 26300 \mu \mathrm{M}$ (Figure S8A) whereas in aorta, ${ }^{43} \mathrm{Gap}$ $26300 \mu \mathrm{M}$ partially inhibited the CGRG to 5-HT (Figure S8B).

$\mathrm{NO}$ and $\mathrm{O}_{2}^{-}$are involved and interconnected in the calcium and contractile responses to $5-\mathrm{HT}$

Since NO is a major element contributing to the endothelial control of vasoreactivity, we checked the effect of L-NAME, a NO 


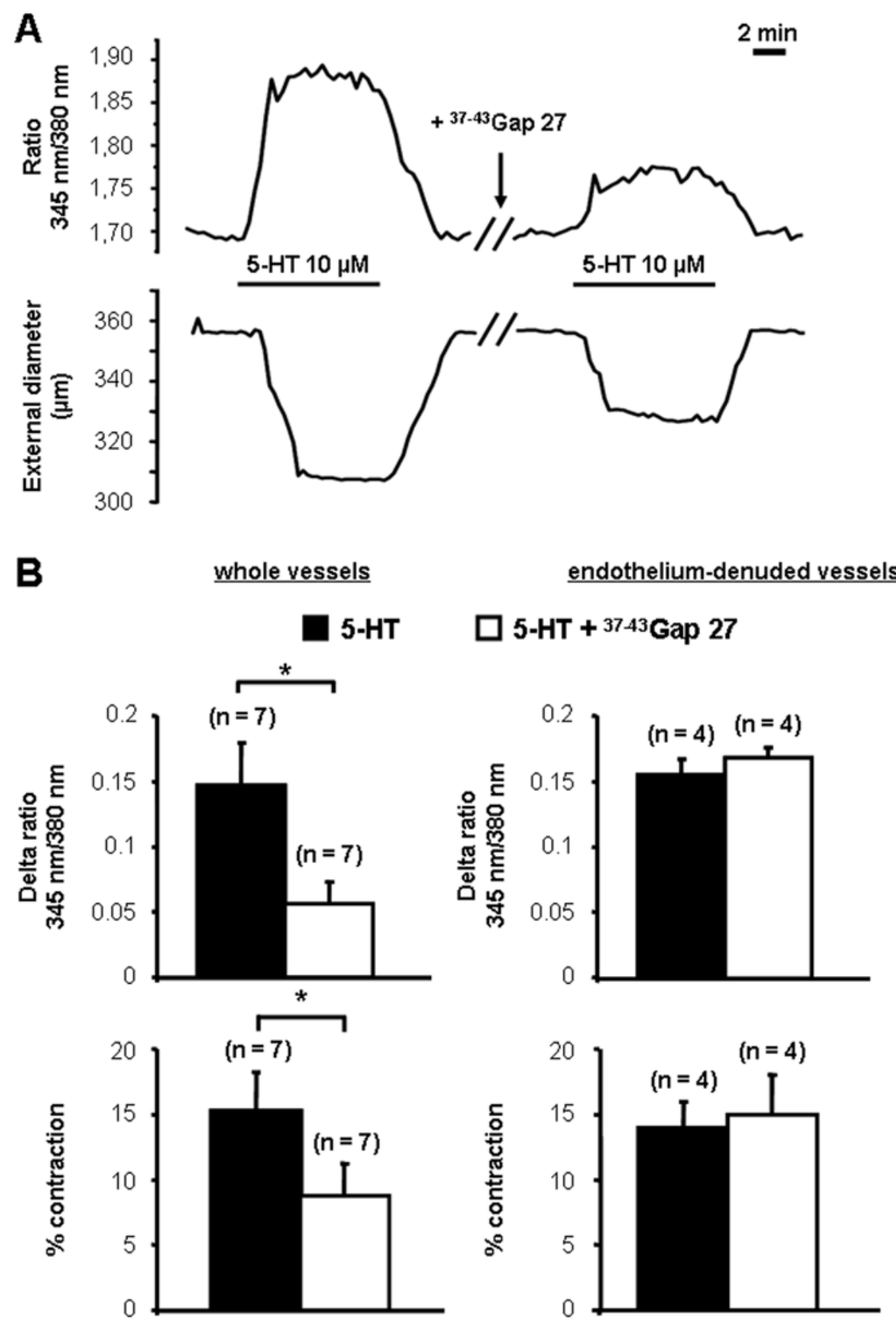

Figure 2. Myoendothelial and/or endothelial gap junctions participate to the calcium and contractile responses to 5-HT. Typical traces of simultaneous recordings of intracellular calcium (top panel) and contraction (bottom panel) induced by 5-HT $10 \mu \mathrm{M}$ are shown in A. $300 \mu \mathrm{M}$ ${ }^{37-43} \mathrm{Gap} 27$ was introduced into the bath where indicated. B shows the mean values \pm S.E.M. for the effect of ${ }^{37-43} \mathrm{Gap} 27$ on both the amplitude of the calcium response to 5-HT $10 \mu \mathrm{M}$ (top) and the percentage of contraction (bottom) in whole vessels (left) and in endothelium-denuded vessels (right). Black columns show the responses to $5-\mathrm{HT}$ in the absence of ${ }^{37-43} \mathrm{Gap} 27$ and white columns are the same responses in the presence of ${ }^{37-43} \mathrm{Gap} 27$. Data are expressed as a delta ratio $(345 \mathrm{~nm} / 380 \mathrm{~nm})$ for calcium signal and the percentage of contraction is related to the percentage of decrease of the initial external diameter. $\mathrm{n}$ indicates the number of vessels studied. ${ }^{*}$ indicates a significant difference when $P<0.05$.

doi:10.1371/journal.pone.0006432.g002

synthase inhibitor, on the blocking effect of ${ }^{37,43}$ Gap 27 previously observed on the simultaneously recorded calcium and contractile signals to 5-HT. L-NAME $100 \mu \mathrm{M}$ reversed the blocking effect of ${ }^{37,43} \mathrm{Gap} 27,300 \mu \mathrm{M}$, on both the intracellular calcium concentration and contraction to 5-HT (Figure 3A) whereas L-NAME $100 \mu \mathrm{M}$ alone had no effect (Figure S9) confirming the importance of NO in the endothelial control of the vasoreactivity through gap junctions. We hypothesized that $\mathrm{O}_{\overline{2}}^{\dot{2}}$ production by 5 -HT could account for a reduction of the endothelial NO production leading to an increased contraction since $\mathrm{O}_{2}^{-}$is a small element which likely passes the membranes through gap junctions and is able to scavenge $\mathrm{NO}$ and/or reduce its production thus decreasing its relaxant effect $[11,27]$. Indeed, poly-ethylene glycol-superoxide dismutase (PEG-SOD) $300 \mathrm{U} / \mathrm{ml}$ and poly-ethylene glycolcatalase (PEG-catalase) $600 \mathrm{U} / \mathrm{ml}$, two substances which catabolise $\mathrm{O} \dot{2}$, reduced calcium and contractile responses to 5 -HT and 

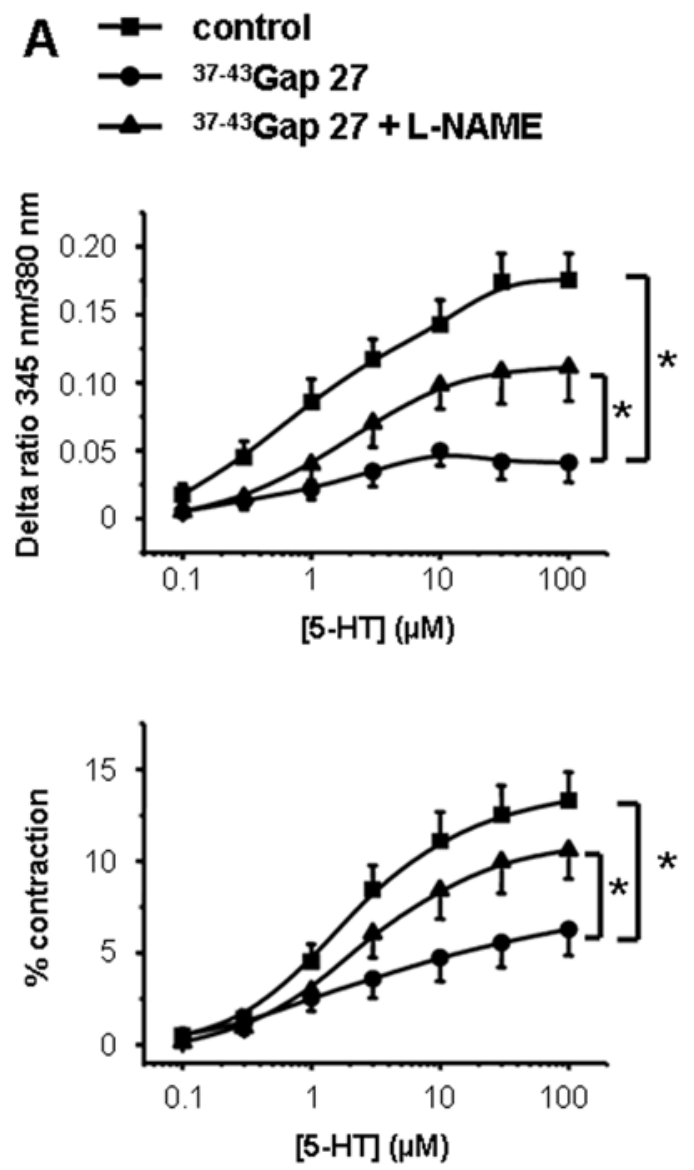
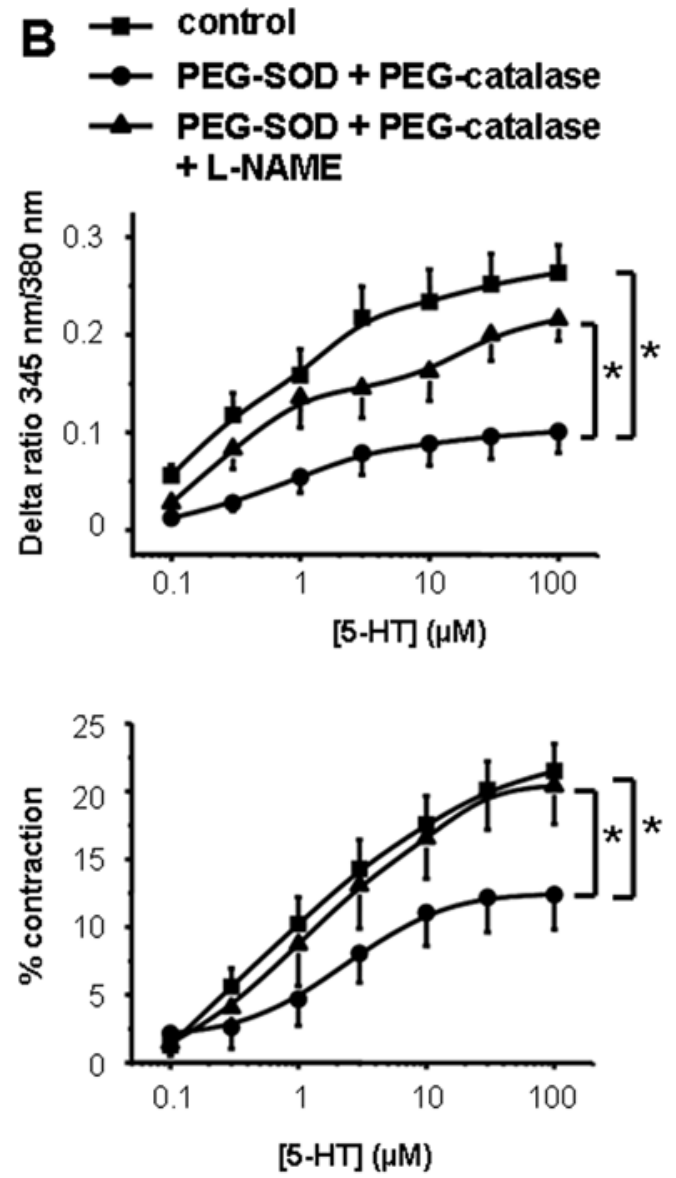

Figure 3. Contribution of gap junctions, $\mathrm{O}_{\mathbf{2}}^{-}$and $\mathrm{NO}$ in the calcium and contractile responses to $\mathbf{5}-\mathrm{HT}$. Concentration response curves to 5-HT $(0.1-100 \mu \mathrm{M})$ were performed simultaneously on the calcium signal (top panels) and the contraction (bottom panels). Data points are means \pm S.E.M. A, $300 \mu \mathrm{M}^{37-43}$ Gap 27 strongly blocked the calcium and contractile signals to 5 -HT (black circles, $n=7$ vessels). B, PEG-SOD (300 U/ml) and PEG-catalase $(600 \mathrm{U} / \mathrm{ml})$ also inhibited the calcium and contractile responses to $5-\mathrm{HT}$ (black circles, $n=7$ vessels). Both ${ }^{37-43} \mathrm{Gap} 27$ and PEG-SOD plus PEG-catalase effects were reversed by L-NAME $100 \mu \mathrm{M}$ ( $A$ and B respectively, black triangles, $n=6$ and 9 vessels respectively). Black squares are control dose-response curves to $5-\mathrm{HT}$ ( $n=13-16$ vessels). * indicates a significant difference when $P<0.05$.

doi:10.1371/journal.pone.0006432.g003

such effect was reversed by L-NAME $100 \mu \mathrm{M}$ (Figure 3B). Electron paramagnetic resonance (EPR) recordings demonstrated that 5 -HT produced $\mathrm{O}_{2}^{\dot{2}}$ (Figure $4 \mathrm{~A}$ ). This $\mathrm{O}_{2}^{\dot{2}}$ production was prevented by PEG-SOD $300 \mathrm{U} / \mathrm{ml}$ and unchanged when the endothelium was removed by CHAPS $0.3 \%$ (Figure $4 \mathrm{~A}$ ). We checked that CHAPS $0.3 \%$ had no effect on its own on basal $\mathrm{O}_{\overline{2}}^{\dot{0}}$ levels (Figure S10). Consequently, 5-HT produced $\mathrm{O}_{2}^{\dot{2}}$ originating from smooth muscle. Moreover, we also directly detected the production of NO by 5-HT with EPR experiments (Figure 4B). When the vessels were endothelium-denuded by CHAPS or treated with L-NAME $100 \mu \mathrm{M}$, the production of NO by 5 -HT was abolished (Figure 4B) showing respectively that 1) NO produced by 5 -HT originates from the endothelium and 2) the product detected by EPR is linked to NO synthases.

Finally, since, on one hand, 5-HT produced NO that induced relaxation via cGMP production in $\mathrm{SMC}$ and, on the other hand, it also produced $\mathrm{O}_{\overline{2}}^{\dot{-}}$ that antagonized $\mathrm{NO}$, we measured the cGMP content in order to determine if the overall result was in favor of a relaxant or a contractile effect. Whereas 5-HT significantly reduced the basal cGMP content, in the additional presence of PEG-SOD $300 \mathrm{U} / \mathrm{ml}$ and PEG-catalase $600 \mathrm{U} / \mathrm{ml}$, it did increase the cGMP content (Figure 4G). This result indicates that $\mathrm{O} \dot{2}$ produced by $5-\mathrm{HT}$ in SMC decreases the NO produced by 5-HT in EC, thus decreasing cGMP level leading to an increased vascular contraction (Figure 5A). To the best of our knowledge, this is the first description of a negative feedback of smooth muscle on endothelial relaxant control of vasoreactivity.

\section{Discussion}

Our findings provide the first direct evidence of a smooth muscle negative feedback on NO-dependent endothelial vasodilatation thus maintaining some contraction in vessels under physiological pressures. In particular, we showed that the $\mathrm{Cx} 43$ is expressed and functional in IPA and is necessary to develop a sustained agonist-mediated contraction in an integrated vascular model. Our data also support that such process involves agonistinduced production of $\mathrm{O}_{2}^{\dot{亠}}$ in the smooth muscle and $\mathrm{NO}$ in the endothelium. $\mathrm{O}_{2}^{\dot{2}}$, via myoendothelial junctions, reduces $\mathrm{NO}$ induced cGMP production in smooth muscle and the resulting vessel relaxation (Figure 5).

In small vessels, gap junctions are usually mainly involved in spontaneous oscillations of membrane potential, intracellular calcium concentration and contraction [24,28,29]. Gap junctions have also been shown to be largely implicated in the mediatorsand endothelium-related relaxation [5,30]. Few studies have 
A
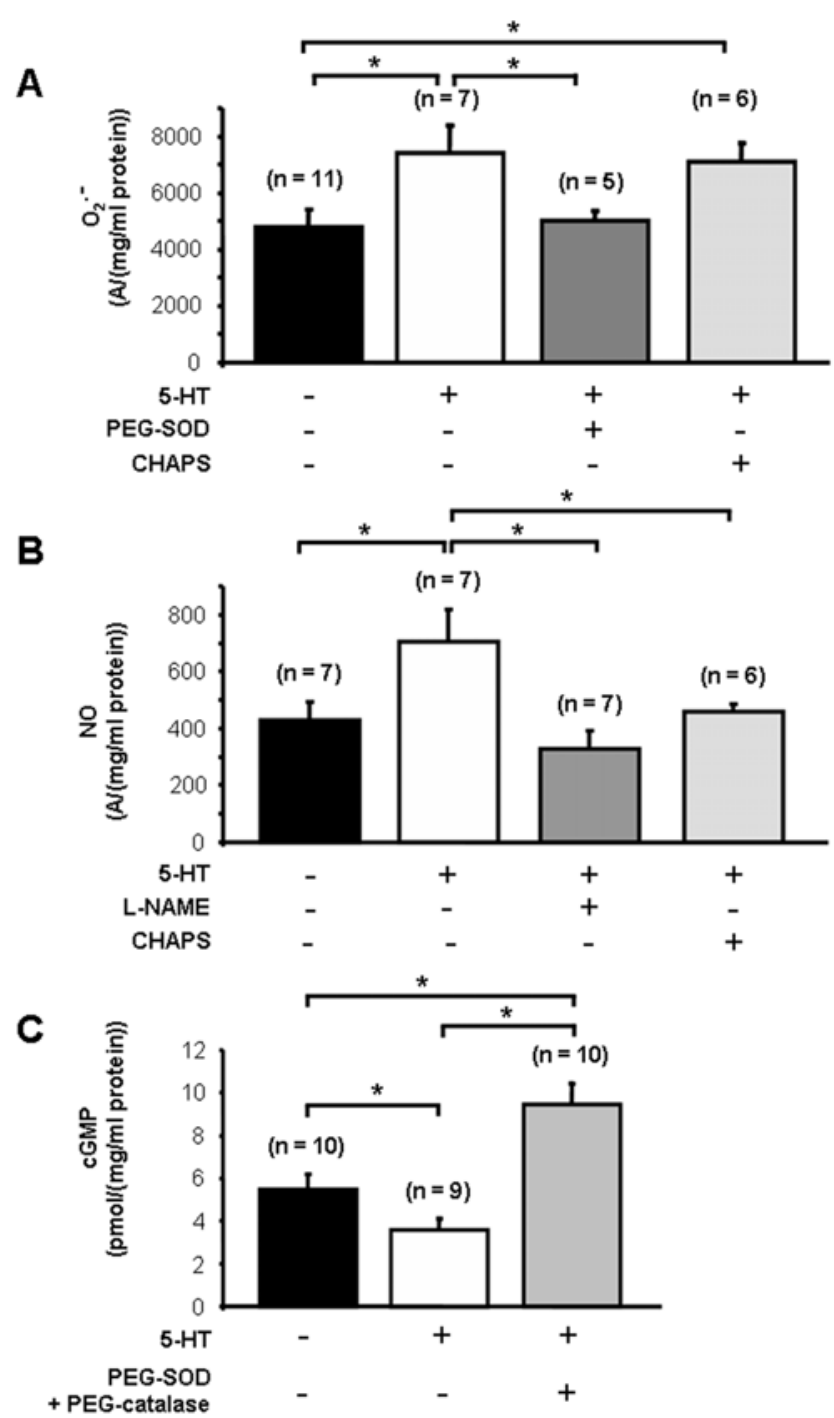

Figure 4. Production of $\mathrm{O}_{2}^{\circ}, \mathrm{NO}$ and cyclic GMP by 5-HT. $\mathrm{A}, \mathrm{O}_{2}^{-}$ production was measured by EPR spectrometry in the absence or in the presence of $5-\mathrm{HT} 100 \mu \mathrm{M}$ (black column and white column respectively). The production of $\mathrm{O}_{2}^{-}$by $5-\mathrm{HT}$ was reduced by PEG-SOD (A, grey column) whereas it was unchanged when vessels were endotheliumdenuded by CHAPS (A, light grey column). B, EPR spectrometry also showed an increase in NO production by $5-\mathrm{HT} 100 \mu \mathrm{M}$ (white column) and an absence of NO production by $5-\mathrm{HT} 100 \mu \mathrm{M}$ when vessels were endothelium-denuded by CHAPS (light grey column) or treated with LNAME $100 \mu \mathrm{M}$ (grey column). C, as measured by Elisa kit, basal cyclic GMP content (black column) was decreased by $5-\mathrm{HT}$ (white column) whereas it was increased when PEG-SOD and PEG-catalase were added to 5-HT (light grey column). Data from EPR spectrometry are expressed as a ratio of the amplitude of the pic (A) out of the protein concentration of each pool of vessels in $\mathrm{mg} / \mathrm{ml}$. cGMP contents are expressed as a ratio of the quantity of cGMP in picomoles out of the protein concentration of each pool of vessels in $\mathrm{mg} / \mathrm{ml}$. Values are means \pm S.E.M. and $\mathrm{n}$ indicates the number of rats tested. ${ }^{*}$ indicates a significant difference when $P<0.05$.

doi:10.1371/journal.pone.0006432.g004

addressed the role of gap junctions in agonist-induced contraction and the results vary according to studies. Indeed, gap junction blockers either increase or decrease the contraction and intracellular calcium to phenylephrine in rat mesenteric arteries [24,29]. Interestingly, arteries that express Cx 43 to a high degree, such as the rat aorta, are more sensitive to adrenergic agonists than those expressing Cx 43 at a low level such as the caudal artery [30,31]. Altogether, these results are consistent with our study namely stimulation of gap junctions, and especially $\mathrm{Cx} 43$, is important to strengthen the agonist-related vascular contraction. However, the mechanisms involved in this regulation of the vascular tone by gap junctions remain elusive.

Gap 26 and Gap 27 connexin-mimetic peptides have been largely used as specific blockers of the gap junctions [24,32]. In our hands, ${ }^{37-43}$ Gap 27 and ${ }^{43}$ Gap 26, firstly, inhibited the calcium and contractile signals to 5 - $\mathrm{HT}$ whereas the inactive analog ${ }^{43} \mathrm{Gap}$ 20 had no effect and, secondly, ${ }^{37-43}$ Gap 27 prevented the diffusion of a fluorescent dye from the endothelial cells to the smooth muscle cells demonstrating the specificity of these blockers on the connexins.

In vessels, $\mathrm{Ca}^{2+}$ and inositol $1,4,5$ trisphosphate $\left(\mathrm{IP}_{3}\right)$ are intercellular messengers that pass through the intercellular communications and especially the myoendothelial communications $[28,33]$. In a model of cocultured endothelial and smooth muscle cells, both $\mathrm{IP}_{3}$ and calcium originating in the vascular SMC appear to cross myoendothelial communications to induce a secondary calcium increase in endothelial cells whereas only calcium, and not $\mathrm{IP}_{3}$, originating from $\mathrm{EC}$ crosses myoendothelial junctions to generate a calcium dependent response in the vascular SMC [33]. In an integrated model of pressurized mesenteric arteries, such regulation by surrounding SMC via myoendothelial gap junctions, even under basal conditions, has also been described [28]. However, under those conditions, $\mathrm{IP}_{3}$ from $\mathrm{SMC}$ increases calcium in EC and, consequently, enhances endothelium-related relaxation rather than contraction. In our study, the negative control of this secondary endothelial calcium signal linked to relaxation allows the smooth muscle to produce a sustained rather than a transient contraction.

There are some lines of evidence from the literature that $\mathrm{O}_{2}^{\dot{2}}(1)$ is produced by 5 -HT in mice and bovine pulmonary arterial SMC and (2) participates to the contraction or proliferation of SMC [10,34]. Although, Liu and Folz [10] used an integrated model of mouse intrapulmonary arteries, they did not address the role of gap junctions in the contraction to 5-HT. In pulmonary artery, 5$\mathrm{HT}$ is well known to induce contraction via stimulation of 5-HT receptors and SMC proliferation via stimulation of 5-HT transporter and/or 5-HT receptors [6]. $\mathrm{O}_{2}^{\dot{*}}$ production in mice intrapulmonary arteries is insensitive to GR 127935, a selective inhibitor of $5-\mathrm{HT} 1 \mathrm{~B} / \mathrm{D}$ receptor and it is sensitive to $5-\mathrm{HT}$ transporter in bovine pulmonary arterial SMC [10,35]. We did not address the role of 5-HT transporter and/or receptor in our model as this issue deserves future study. In the same way, Liu and Folz suggested that $\mathrm{O}_{2}^{\dot{亠}}$ was produced via a NADPH oxidase pathway [10] and this hypothesis could apply to our study.

$\mathrm{O}_{2}^{-}$is increased in several models of hypertension including pulmonary arterial hypertension [36,37]. Moreover, it has been observed that increased contraction to 5-HT in aortic strips of hypertensive rats is inhibited by the blockade of the gap junctions [38]. Finally, pulmonary arterial hypertension is linked to an endothelial dysfunction [39]. These data suggest that the process we propose, namely the negative regulation of the endothelial relaxation by the smooth muscle, could also be of great interest in vascular pathophysiological conditions.

In conclusion, we evidenced vascular smooth muscle can negatively control the endothelial relaxation in order to produce a sustained contraction in small vessels at physiological pressures. This control involves $\mathrm{O} \dot{\overline{2}}$, myoendothelial junctions and regulation of endothelial NO function. In that respect, modifications of this process could potentially be involved in vascular pathologies and need to be further investigated. 
A

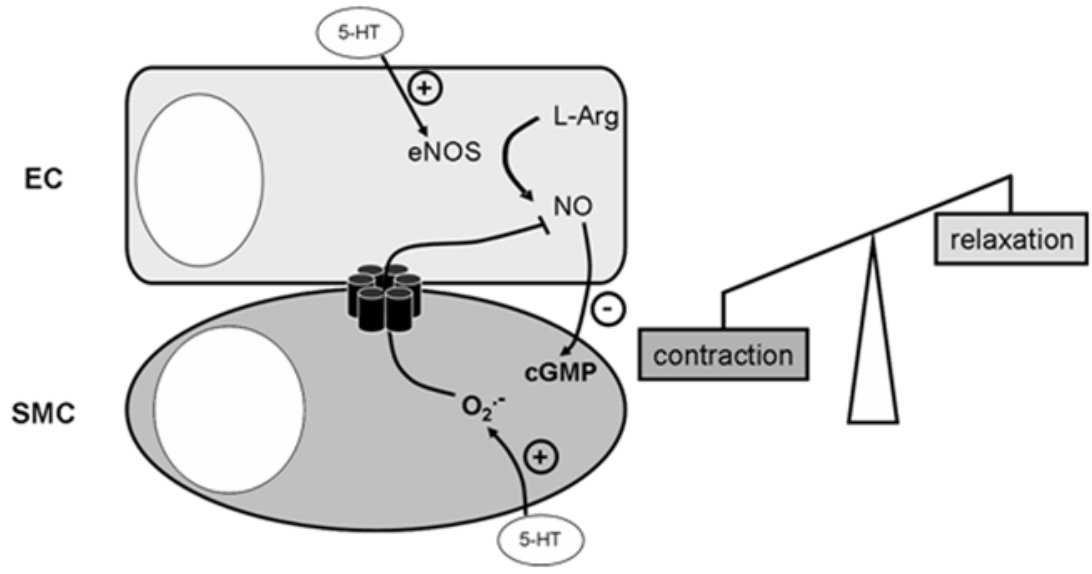

B

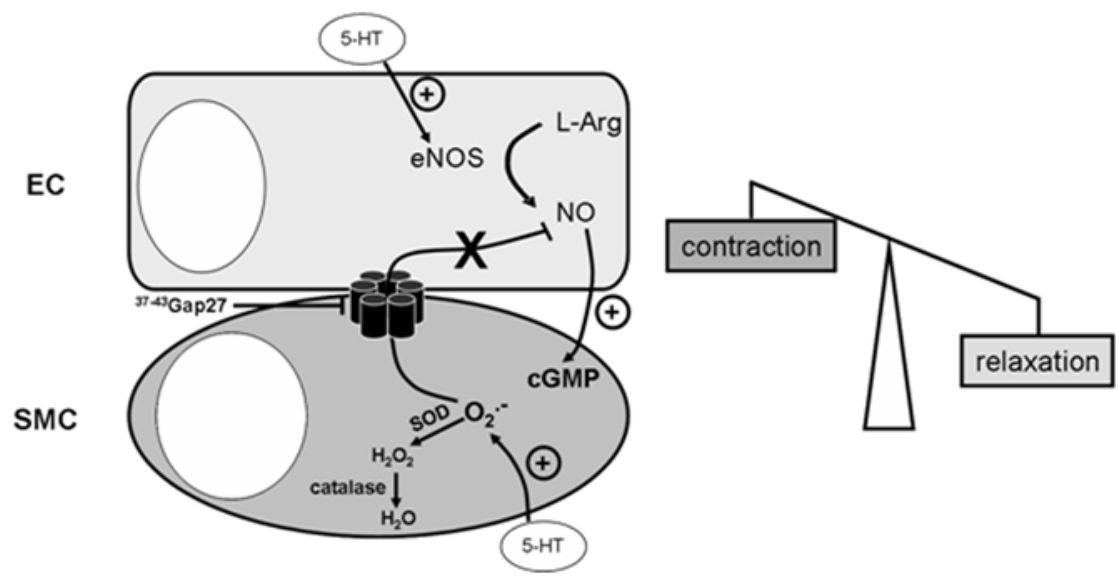

Figure 5. Proposed mechanism for the negative feedback of smooth muscle on endothelial relaxant control of vasoreactivity. 5-HT can act on both SMC and EC. Calcium increase in SMC in response to 5-HT leads to contraction whereas in EC it stimulates NO synthase and leads to NO production. NO will stimulate guanylate cyclase which will increase CGMP production in SMC and then induce relaxation. In normal conditions, 5$\mathrm{HT}$ produces $\mathrm{O}_{\overline{2}}^{-}$in SMC. $\mathrm{O}_{\overline{2}}^{-}$passes through myoendothelial gap junctions and scavenges NO in EC thus decreasing cGMP content in SMC. Consequently, $5-\mathrm{HT}$ effect on SMC prevails over $5-\mathrm{HT}$ effect on $\mathrm{EC}$ and will induce a contraction (A). If (1) $\mathrm{O}_{2}^{-}$is degraded by SOD and catalase, and/or (2) gap junctions are blocked, NO scavenging by $\mathrm{O}_{2}^{-}$in EC will be prevented. Consequently, NO and cGMP levels will be increased thus inducing a relaxant effect leading to a lower contraction to $5-\mathrm{HT}$ in the whole vessels (B).

doi:10.1371/journal.pone.0006432.g005

\section{Supporting Information}

Figure S1 Reproducibility of two cumulative concentrationresponse curves to 5-HT on the same vessel. Two CCRC to 5-HT $(0.1-100 \mu \mathrm{M})$ recorded on the same vessel with a delay of one hour in between the two curves were similar for both calcium signal (top) and contraction (bottom). Black squares indicate the first CGRC and the black circles indicate the second CGRC. Data are means \pm S.E.M. for 8 vessels and are expressed as a delta ratio $(345 \mathrm{~nm} / 380 \mathrm{~nm})$ for calcium signal and a percentage of contraction (top and bottom respectively). The percentage of contraction is related to the percentage of the initial external diameter.

Found at: doi:10.1371/journal.pone.0006432.s001 (0.30 MB TIF)

Figure S2 Effect of endothelium removal on the relaxant effect of carbamylcholine. Intrapulmonary arteries were preconstricted with high potassium solution $(\mathrm{KCl} 40 \mathrm{mM})$ and then stimulated with $10 \mu \mathrm{M}$ carbamylcholine. Calcium and contractile signals were simultaneously recorded (top and bottom respectively). The experiments were performed in control vessels (black column) and in vessels whose endothelium has been denuded with CHAPS (white column). Data are means \pm S.E.M. and are expressed as a percentage of the delta ratio $(345 \mathrm{~nm} / 380 \mathrm{~nm})$ or a percentage of the contraction in response to carbamylcholine $10 \mu \mathrm{M}$ from preconstricted vessels with $\mathrm{KCl} 40 \mathrm{mM}$ (top and bottom respectively). $\mathrm{n}$ indicates the number of vessels tested. * indicates a significant difference when $\mathrm{P}<0.05$.

Found at: doi:10.1371/journal.pone.0006432.s002 (0.21 MB TIF)

Figure S3 Effect of endothelium removal on the calcium and contractile responses to high potassium solution. The calcium and contractile signals simultaneously recorded in response to high potassium solution $(\mathrm{KCl} 40 \mathrm{mM}$ ) were similar in control vessels (black column) and in vessels whose endothelium has been denuded with CHAPS (white column). Data are means \pm S.E.M. and are expressed as a delta ratio $(345 \mathrm{~nm} / 380 \mathrm{~nm})$ for calcium signal and a percentage of contraction (top and bottom respectively). $\mathrm{n}$ indicates the number of vessels tested.

Found at: doi:10.1371/journal.pone.0006432.s003 (0.19 MB TIF)

Figure S4 Effect of 40Gap 27 on the calcium and contractile signals in response to 5-HT. The calcium and contractile signals were simultaneously recorded in response to 5 -HT $10 \mu \mathrm{M}$ in the absence (black column) or in the presence of $300 \mu \mathrm{M} 40 \mathrm{Gap} 27$, 
the Cx-mimetic peptide targeted against Cx 40 (white column). Data are means \pm S.E.M. and are expressed as a delta ratio $(345 \mathrm{~nm} / 380 \mathrm{~nm})$ for calcium signal and a percentage of contraction (top and bottom respectively). $\mathrm{n}$ indicates the number of vessels tested.

Found at: doi:10.1371/journal.pone.0006432.s004 (0.18 MB TIF)

Figure S5 Effect of 43Gap 26 on the calcium and contractile signals in response to 5-HT. Cumulative concentration-response curves to 5-HT $(0.1-100 \mu \mathrm{M})$ were performed in the absence or in the presence of $300 \mu \mathrm{M}$ 43Gap 26, the Cx-mimetic peptide targeted against $\mathrm{Cx} 43$ (black squares and circles respectively). Data are means \pm S.E.M. for 7 vessels and are expressed as a delta ratio $(345 \mathrm{~nm} / 380 \mathrm{~nm})$ for calcium signal and a percentage of contraction (top and bottom respectively). * indicates a significant difference when $\mathrm{P}<0.05$.

Found at: doi:10.1371/journal.pone.0006432.s005 (0.30 MB TIF)

Figure S6 Effect of 43Gap 20 on the calcium and contractile signals in response to 5 -HT. CCRC to 5 -HT $(0.1-100 \mu \mathrm{M})$ were performed in the absence or in the presence of $300 \mu \mathrm{M} 43 \mathrm{Gap} 20$, an inactive analog of the $\mathrm{Cx}$-mimetic peptide targeted against $\mathrm{Cx}$ 43 (black squares and circles respectively). Data are means \pm S.E.M. for 7 vessels and are expressed as a delta ratio $(345 \mathrm{~nm} / 380 \mathrm{~nm})$ for calcium signal and a percentage of contraction (top and bottom respectively).

Found at: doi:10.1371/journal.pone.0006432.s006 (0.30 MB TIF)

Figure S7 Effect of 37-43Gap 27 on the contractile responses to 5-HT, phenylephrine, endothelin-1 and high potassium solutions. Isometric tension measurements were recorded on intrapulmonary arterial rings in response to cumulative concentrations of 5-HT (A) or phenylephrine $(\mathrm{B})$ or endothelin-1 $(\mathrm{C})$ or in response to increasing concentrations of potassium (KCl $4.7-100 \mathrm{mM})(\mathrm{D})$. Contractions were recorded in the absence (black squares) or in the presence (black circles) of $300 \mu \mathrm{M}$ 37-43Gap 27. Data are means \pm S.E.M. for $7-21$ vessel rings and are expressed as a percentage of the contraction to high potassium solution $(\mathrm{KCl}$ $80 \mathrm{mM})$. * indicates a significant difference when $\mathrm{P}<0.05$.

Found at: doi:10.1371/journal.pone.0006432.s007 (0.41 MB TIF)

Figure S8 Effect of 43Gap 26 on the contractile responses to 5HT in renal arteries and aorta. Isometric tension measurements were recorded on arterial rings in response to cumulative

\section{References}

1. Furchgott RF, Vanhoutte PM (1989) Endothelium-derived relaxing and contracting factors. Faseb J 3: 2007-2018.

2. Quilley J, McGiff JC (2000) Is EDHF an epoxyeicosatrienoic acid? Trends Pharmacol Sci 21: 121-124.

3. Edwards G, Dora KA, Gardener MJ, Garland CJ, Weston AH (1998) K+ is an endothelium-derived hyperpolarizing factor in rat arteries. Nature 396: 269-272.

4. Chaytor AT, Edwards DH, Bakker LM, Griffith TM (2003) Distinct hyperpolarizing and relaxant roles for gap junctions and endothelium-derived $\mathrm{H} 2 \mathrm{O} 2$ in NO-independent relaxations of rabbit arteries. Proc Natl Acad Sci U S A 100: 15212-15217.

5. Morio Y, Carter EP, Oka M, McMurtry IF (2003) EDHF-mediated vasodilation involves different mechanisms in normotensive and hypertensive rat lungs. Am J Physiol Heart Circ Physiol 284: H1762-1770.

6. Dempsie Y, MacLean MR (2008) Pulmonary hypertension: therapeutic targets within the serotonin system. Br J Pharmacol 155: 455-462.

7. Rodat L, Savineau JP, Marthan R, Guibert C (2007) Effect of chronic hypoxia on voltage-independent calcium influx activated by 5 -HT in rat intrapulmonary arteries. Pflugers Arch 454: 41-51.

8. Jahnichen S, Glusa E, Pertz HH (2005) Evidence for 5-HT2B and 5-HT7 receptor-mediated relaxation in pulmonary arteries of weaned pigs. Naunyn Schmiedebergs Arch Pharmacol 371: 89-98.

9. Lee SL, Simon AR, Wang WW, Fanburg BL (2001) $\mathrm{H}(2) \mathrm{O}(2)$ signals 5-HTinduced ERK MAP kinase activation and mitogenesis of smooth muscle cells. Am J Physiol Lung Cell Mol Physiol 281: L646-652. concentrations of 5-HT in renal arteries (A) or aorta (B). Contractions were recorded in the absence (black squares) or in the presence (black circles) of $300 \mu \mathrm{M} 43 \mathrm{Gap} 26$. Data are means \pm S.E.M. for 8 - 16 vessel rings and are expressed as a percentage of the contraction to high potassium solution $(\mathrm{KCl}$ $80 \mathrm{mM}$ ). * indicates a significant difference when $\mathrm{P}<0.05$.

Found at: doi:10.1371/journal.pone.0006432.s008 (0.29 MB TIF)

Figure S9 Effect of L-NAME on the simultaneously recorded calcium and contractile signals in response to 5-HT. Cumulative concentration-response curves to 5-HT $(0.1-100 \mu \mathrm{M})$ were performed in the absence or in the presence of L-NAME $100 \mu \mathrm{M}$, a NO synthase inhibitor (black squares and circles respectively). Data are means \pm S.E.M. for 6 vessels and are expressed as a delta ratio $(345 \mathrm{~nm} / 380 \mathrm{~nm})$ for calcium signal and a percentage of contraction (top and bottom respectively).

Found at: doi:10.1371/journal.pone.0006432.s009 (0.29 MB TIF)

Figure S10 Effect of endothelium removal and xanthine plus xanthine oxidase treatment on superoxide anion production. O2• was measured by using CMH spin trapping method and EPR spectrometry on control vessels (black column), vessels whose endothelium was denuded with CHAPS $0.3 \%$ (white column, top panel) and vessels treated with xanthine $50 \mu \mathrm{M}$ plus xanthine oxidase $0.02 \mathrm{U} / \mathrm{ml}$ (white column, bottom panel). Data are means \pm S.E.M. and are expressed as a ratio of the amplitude of the pic (A) out of the protein concentration of each pool of vessels in $\mathrm{mg} / \mathrm{ml} . \mathrm{n}$ indicates the number of vessels tested.

Found at: doi:10.1371/journal.pone.0006432.s010 (0.24 MB TIF)

\section{Acknowledgments}

We thank Huguette Crevel for her technical assistance in performing isometric contraction experiments. We also thank Dr Martinez MC and Dr Andriantsitohaina R (CNRS, UMR 6214, INSERM, U771, Universite d'Angers - France) for their helpful advices regarding Electron Paramagnetic Resonance.

\section{Author Contributions}

Conceived and designed the experiments: MB GG. Performed the experiments: MB CG. Analyzed the data: MB CG. Wrote the paper: MB RM JPS CG.

10. Liu JQ, Folz RJ (2004) Extracellular superoxide enhances 5-HT-induced murine pulmonary artery vasoconstriction. Am J Physiol Lung Cell Mol Physiol 287: L111-118.

11. Dumitrescu C, Biondi R, Xia Y, Cardounel AJ, Druhan LJ, et al. (2007) Myocardial ischemia results in tetrahydrobiopterin (BH4) oxidation with impaired endothelial function ameliorated by $\mathrm{BH} 4$. Proc Natl Acad Sci U S A 104: 15081-15086.

12. Figueroa XF, Isakson BE, Duling BR (2004) Connexins: gaps in our knowledge of vascular function. Physiology (Bethesda) 19: 277-284

13. Ko YS, Yeh HI, Rothery S, Dupont E, Coppen SR, et al. (1999) Connexin make-up of endothelial gap junctions in the rat pulmonary artery as revealed by immunoconfocal microscopy and triple-label immunogold electron microscopy. J Histochem Cytochem 47: 683-692.

14. Nakamura K, Inai T, Nakamura K, Shibata Y (1999) Distribution of gap junction protein connexin 37 in smooth muscle cells of the rat trachea and pulmonary artery. Arch Histol Cytol 62: 27-37.

15. Moore LK, Burt JM (1995) Gap junction function in vascular smooth muscle: influence of serotonin. Am J Physiol 269: H1481-1489.

16. Sandow SL, Hill CE (2000) Incidence of myoendothelial gap junctions in the proximal and distal mesenteric arteries of the rat is suggestive of a role in endothelium-derived hyperpolarizing factor-mediated responses. Circ Res 86: 341-346.

17. Guibert C, Marthan R, Savineau JP (2004) 5-HT induces an arachidonic acidsensitive calcium influx in rat small intrapulmonary artery. Am J Physiol Lung Cell Mol Physiol 286: L1228-1236. 
18. Robert R, Savineau JP, Norez G, Becq F, Guibert C (2007) Expression and function of cystic fibrosis transmembrane conductance regulator in rat intrapulmonary arteries. Eur Respir J 30: 857-864.

19. Guibert C, Savineau JP, Crevel H, Marthan R, Rousseau E (2005) Effect of short-term organoid culture on the pharmaco-mechanical properties of rat extra- and intrapulmonary arteries. Br J Pharmacol 146: 692-701.

20. Bonnet S, Dumas-de-La-Roque E, Begueret H, Marthan R, Fayon M, et al. (2003) Dehydroepiandrosterone (DHEA) prevents and reverses chronic hypoxic pulmonary hypertension. Proc Natl Acad Sci U S A 100: 9488-9493.

21. Meziani F, Kremer H, Tesse A, Baron-Menguy C, Mathien C, et al. (2007) Human serum albumin improves arterial dysfunction during early resuscitation in mouse endotoxic model via reduced oxidative and nitrosative stresses. Am J Pathol 171: 1753-1761.

22. Kleschyov AL, Mollnau H, Oelze M, Meinertz T, Huang Y, et al. (2000) Spin trapping of vascular nitric oxide using colloid $\mathrm{Fe}(\mathrm{II})$-diethyldithiocarbamate. Biochem Biophys Res Commun 275: 672-677.

23. Vandesompele J, De Preter K, Pattyn F, Poppe B, Van Roy N, et al. (2002) Accurate normalization of real-time quantitative RT-PCR data by geometric averaging of multiple internal control genes. Genome Biol 3: RESEARCH0034.

24. Matchkov VV, Rahman A, Bakker LM, Griffith TM, Nilsson H, et al. (2006) Analysis of effects of connexin-mimetic peptides in rat mesenteric small arteries. Am J Physiol Heart Circ Physiol 291: H357-367.

25. Saliez J, Bouzin C, Rath G, Ghisdal P, Desjardins F, et al. (2008) Role of caveolar compartmentation in endothelium-derived hyperpolarizing factormediated relaxation: $\mathrm{Ca} 2+$ signals and gap junction function are regulated by caveolin in endothelial cells. Circulation 117: 1065-1074.

26. Chaytor AT, Evans WH, Griffith TM (1997) Peptides homologous to extracellular loop motifs of connexin 43 reversibly abolish rhythmic contractile activity in rabbit arteries. J Physiol 503 ( Pt 1): 99-110.

27. Beckman JS, Beckman TW, Chen J, Marshall PA, Freeman BA (1990) Apparent hydroxyl radical production by peroxynitrite: implications for endothelial injury from nitric oxide and superoxide. Proc Natl Acad Sci U S A 87: 1620-1624.
28. Kansui Y, Garland CJ, Dora KA (2008) Enhanced spontaneous Ca2+ events in endothelial cells reflect signalling through myoendothelial gap junctions in pressurized mesenteric arteries. Cell Calcium 44: 135-146.

29. Schuster A, Oishi H, Beny JL, Stergiopulos N, Meister JJ (2001) Simultaneous arterial calcium dynamics and diameter measurements: application to myoendothelial communication. Am J Physiol Heart Circ Physiol 280: H1088-1096.

30. Rocha ML, Kihara AH, Davel AP, Britto LR, Rossoni LV, et al. (2008) Blood pressure variability increases connexin expression in the vascular smooth muscle of rats. Cardiovasc Res 80: 123-130.

31. Rummery NM, Hickey H, McGurk G, Hill CE (2002) Connexin37 is the major connexin expressed in the media of caudal artery. Arterioscler Thromb Vasc Biol 22: 1427-1432.

32. Griffith TM, Chaytor AT, Taylor HJ, Giddings BD, Edwards DH (2002) cAMP facilitates EDHF-type relaxations in conduit arteries by enhancing electrotonic conduction via gap junctions. Proc Natl Acad Sci U S A 99: 6392-6397.

33. Isakson BE, Ramos SI, Duling BR (2007) Ca2+ and inositol 1,4,5-trisphosphatemediated signaling across the myoendothelial junction. Circ Res 100: 246-254.

34. Lee SL, Wang WW, Finlay GA, Fanburg BL (1999) Serotonin stimulates mitogen-activated protein kinase activity through the formation of superoxide anion. Am J Physiol 277: L282-291.

35. Lee SL, Wang WW, Fanburg BL (1998) Superoxide as an intermediate signal for serotonin-induced mitogenesis. Free Radic Biol Med 24: 855-858.

36. Liu JQ, Zelko IN, Erbynn EM, Sham JS, Folz RJ (2006) Hypoxic pulmonary hypertension: role of superoxide and NADPH oxidase (gp91phox). Am J Physiol Lung Cell Mol Physiol 290: L2-10.

37. Lyle AN, Griendling KK (2006) Modulation of vascular smooth muscle signaling by reactive oxygen species. Physiology (Bethesda) 21: 269-280.

38. Watts SW, Webb RC (1996) Vascular gap junctional communication is increased in mineralocorticoid-salt hypertension. Hypertension 28: 888-893.

39. Coggins MP, Bloch KD (2007) Nitric oxide in the pulmonary vasculature. Arterioscler Thromb Vasc Biol 27: 1877-1885. 